\title{
The Efficacy Of The Virtual: From Che As Sign To Che As Agent
}

\author{
Carolina Cambre ${ }^{1}$, \\ University of London Ontario \\ London, Ontario, Canada
}

\begin{abstract}
This paper begins by tracing a path through salient developments in semiotic theory regarding the visual. It examines the political functions of cultural and discursive semiotic systems through which graphic images and gestures are appraised, interpreted and given significance: it is not about what they mean, but rather how they construct meanings and how such meanings accrue importance. I consider the simultaneous material and social nature of both vision and representation. My primary focus is with the visual and social performance of the image of Che Guevara as derived from Alberto Korda's famous 1960 photograph, El Guerrillero Heroico. Using this image as a heuristic in the case of Che Guevara's image in East Timor during the time of Indonesia's dictatorship and independence struggle, I will outline how the performative aspect creates a space of "ethical possibility" through visualizations. I will tease out anthropologist Alfred Gell's (1997) radical notions of the agency of art and explore the possibilities of Donald Preziosi's (2003) elaboration of Roman Jakobson's addition of a fourth sign type, namely artifice. The inclusion of artifice is underwritten by an understanding of A. J. Greimas'(1987) semiotic square as a way to introduce complexity into binary or dual forms. I posit the square is as a dynamic, fractal-like construction. Building on this foundation, I articulate possible connections between artifice and the notion of the virtual as described by a philosophers and academicians from C.S. Peirce to Rob Shields, as a contribution to this theorizing and explore its relevance to the Che image phenomenon. Overall, it is the desire to find ways to speak about the Guerrillero Heroico's social and political activity and resonance that drives the theoretical contributions in this piece.
\end{abstract}

\footnotetext{
"Aixo era y no era"

(It was and it was not).
}

Majorca storytellers

"In the contradiction lies the hope"

Bertold Brecht

1 carolina.cambre@ualberta.ca 


\section{Introduction}

My search for a way to talk about an image -an image that began as a photograph but one that soon assumed different social, cultural and political functions: the banner in a parade, the graffiti in a camp, and a bikini on the catwalk among other things -led me to semiotics. The media vary as do the times, places, and contexts where everyday people occupy and find themselves interpellated by some rendering of Che Guevara's face that recalls the Korda photo. The key question became how to speak about an image tattooed on Mike Tyson's midriff in the USA for example, at the same time as it is a Bolivian miner's hardhat icon, a Swiss cigarette logo, Chinese actress Fan Bingbing's 'look,' fodder for artists such as Vik Muniz, and a mural for indigenous Zapatista rebels in Chiapas, Mexico. Can these disparate figurations of Che's image be brought into conversation with each other without arbitrarily reducing them?

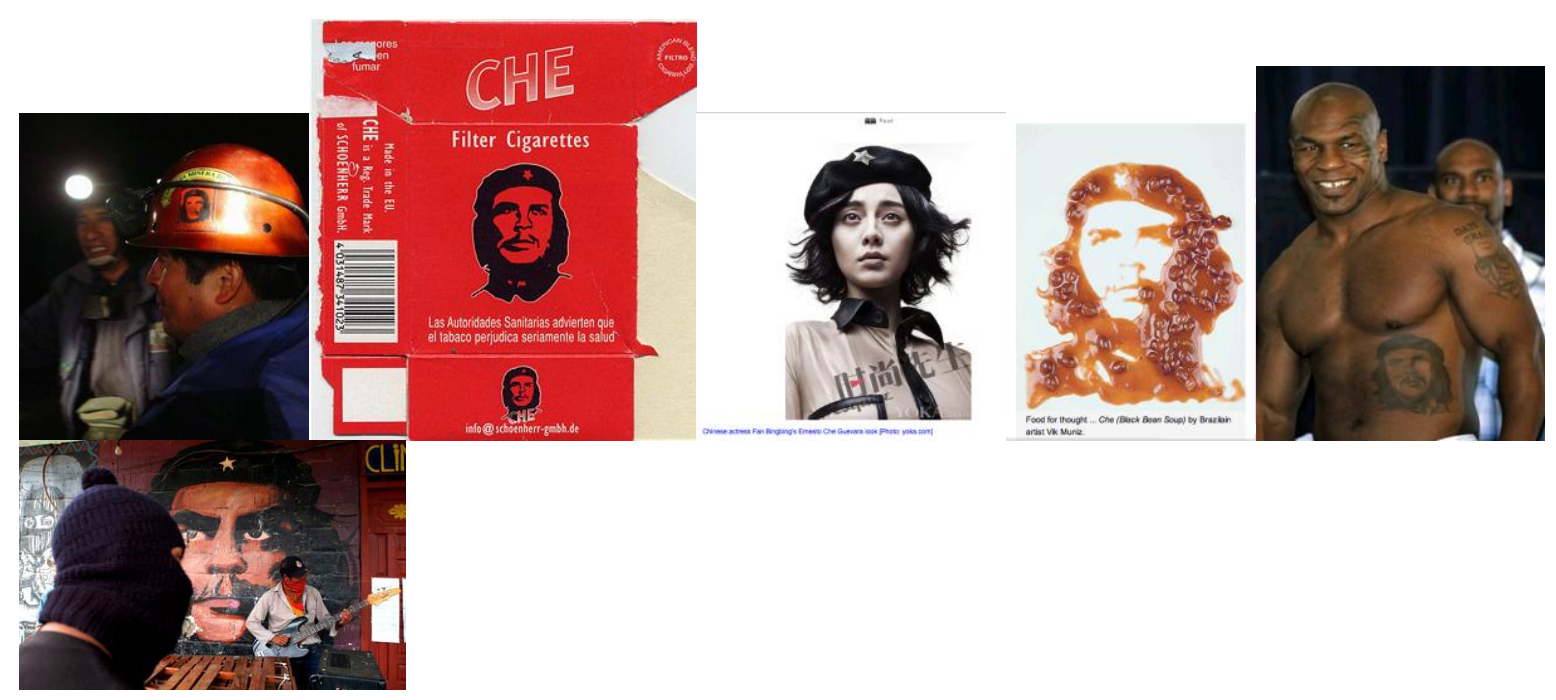

Often semiotics is applied within sociological and anthropological paradigm with an ontological tendency toward reductionism. Knowledge is more than mere information: it encompasses understanding the articulation of information within a constellation of human interests and societal influences beyond a utilitarian paradigm that characterizes so many academic disciplines implicated in technocratic, individualistic and consumerist worldviews. As an instrument to further understanding of our multi-dimensional being in the world, semiotics needs to be correspondingly multi-dimensional. It's useful to recognize how the "academic apartheid" (Sandoval, 2000 p.4) of artificially dividing disciplines (nutrition from medicine being a classic example) actually generates exclusionist epistomologies. Reductionism as a partial vision of a phenomenon stimulates dogmatism. Semiotics has the potential to provide transdisciplinary inclusivity and dialogue, but it must be applied so that the multidimensionality of a phenomenon is kept in view, as well as its limits.

What is the potential offered by semiotic theory as a way to "see" this image and push its limits conceptually and functionally to show how it is not only socially reinvented as part of a "counterpublics"” (Asen and Brouwer 2001; Coleman and Ross 2010) discourse but also to see how it 
authorizes and motivates actors in turn? The purpose of this piece is to engage the thematic/discursive multiplicity essential to Korda's image of Che Guevara while still having some structure to orient myself around it, I approach representation as something that does more than stand for other things. I understand representation in this case, as inseparable from acting and being, it is kinetic, and mimetic. Understanding the term this way gives me permission to incorporate different ways of speaking to/with the object (theoretically and practically in terms of modality i.e. alternatives to text) and that would provide coherence yet allow the results to be emergent.

In the first half of this article, I provide a focused overview of key ideas I collate with an eye to having them inform the case of Che's image. Beginning this way allows me to show where I am situated in semiotics, and subsequently reveals what I am doing differently with regards to relationality, performativity and openness. Subsequently, I can locate the trajectory influenced by Alfred Gell's (1998) anthropological concepts of art and agency and the role of the concept of the virtual.

\section{Semiotics: The history of a broken frame}

Semiotics today operates from post-structural frameworks and can be seen as an open and transitive structurating rather than structural approach. Quite literally, the movement 'poststructuralism' was a transition within one variant of semiotics itself though it happened differently in different schools of thought. For example, it was an earlier and much more belligerent rupture in France than the later, more gradual transition in Italy. Notably, many of the key structuralist figures also became important post-structuralists, the most obvious example being Roland Barthes. Jacques Derrida deconstructed the assumptions underlying structuralism in Structure, sign, and play critiquing Claude Lévi-Straus's Mythologiques among others, and thus changed forever the European philosophical panorama. Speculating that, "perhaps something has occurred in the history of the concept of structure that could be called an event," Derrida observes that the very word event had "a meaning which it is precisely the function of structural — or structuralist - thought to reduce or to suspect" (1978, p. 278). He realized as long as semiotics was oriented towards structure, there would be no room for movement, performativity or play and one stable Truth would calcify at the centre. Many years later, he is echoed by Bal and Bryson (1991) who understand that "to think of semiosis as process and as movement is to conceive the sign not as a thing but as an event, the issue being ... to trace the possible emergence of the sign in a concrete situation, as an event in the world" (p. 196).

The struggle to sustain a structural analysis forced thinkers like Barthes and Lévi-Straus to admit the limits of this paradigm and recognize that, before the rupture initiated by Derrida, they were enacting "a series of substitutions of centre for centre, as a linked chain of determinations of the centre (Gasché, R. 1986 p. 353). Even the rupture, observes Derrida, is structural: it has "the structurality of an opening" but he pushes us to recognize it cannot be so simply understood. "It is thus as little a structure as it is an opening; it is as little static as it is genetic, as little structural as it is historical. It can be understood neither from a genetic nor from a structuralist and taxonomic point of view, nor from a combination of both points of view" (Gasché p. 146). An opening still needs a frame to be seen as an opening. The intimate and inseparable relationship between structuralism and its 'post' cannot be forgotten, clearly, that empty centre, or lack, can also be seen as a structural element.

With regards to the case of Che Guevara's image, one can now ask: what then, is the essential 
quality of a work of art or an art form? It is not about communication in the Lockean sense of understanding something by bringing it to the Same, or the consensus model, rather it is an interruption. It is an event, and thus calls for comment but does not necessarily condescend to become whatever someone wants to make of it.

Further, semiotics is "centrally concerned with reception"; in fact, its object is to describe the "conventions and conceptual operations" shaping what viewers do; “...it will not provide or even discover a meaning but will describe the logic according to which meanings are engendered" (Bal \& Bryson, 1991 p. 186). Crucially, semiotics recognizes there are many other viewers besides those whose observations can be discovered:

... As a canon has its exclusions, so has an archive: we need to look away from the obvious traces and the official records of reception, in order make the archive admit those whom it has set aside (Bal \& Bryson, 1991 p. 187, original emphasis).

The numberless trajectories of seeing made possible in the visual text does not mean that reception is abandoned as a goal, rather the claim is shifted to one of asking: "From where, from what position, is the reconstruction being made?" (Bal \& Bryson, 1991 pp. 187-189) If we understand reception in the manner being described by Bal and Bryson we must acknowledge viewers are being constructed by the object viewed at the very moment their viewing is also constructing the object. Thus, reception is always simultaneously production [and a kind of immersion]. Here, C.S. Peirce's definition of meaning is critical. Peirce asserts that meaning is "in its primary acceptation, the translation of a sign into another system of signs" (Eco, 1976, p. 1464). But the process is continuous; it can be followed, so it is like a metamorphosis rather than a metaphor. This dynamic view of the sign, "can help to denaturalize the exclusions that have resulted from those particular framings, as well as, conversely, to use framings to counter these exclusions without falling back into positivistic claims to truth" (Bal \& Bryson, 1991 p. 204) and helps make the analysis historically responsible.

Since all grammars (structures) leak as Edward Sapir famously noted, Chandler (2002) recommends searching for structural leaks, seams and scaffolding as signs of a representation's construction, as well as obfuscation (p. 58). Another voice in the dialogue, John Tagg, comments that he is "not concerned with exposing the manipulation of a pristine 'truth', or with unmasking some conspiracy, but rather with the analysis of the specific 'political economy' within which the 'mode of production' of 'truth' is operative" (1988, 174-5 in Chandler, 2002, p. 165). The question for me becomes, how can Che Guevara's image be recognized, which features of the Che image are indispensable in terms of a viewer's ability to relate the translation to the original photograph or at least its interpretants in their minds and understand something by the altered renderings?

Pressing forward, it is helpful to keep interrelated debates in mind as well as the "elementary ideas that underlie Peirce's" (p. 1539) inquiry that Jakobson (1976) sums up as the problem of the role of symbols in our creative life. Jakobson would later elaborate a fourth essential kind of sign to assist the study of the role of symbols. Though he did not publish his work in this area, we are aware of this development through Donald Preziosi (2003) who mentions his conversations with Jakobson and how they debated this fourth term. This fourth, the artifice, will be central to my development of a theoretical frame. In what follows, I will outline some of Jakobson's and Preziosi's ideas, and attend to them in more depth. 
For background, Preziosi's concern with the impossibilities of representation prompt him to explore the implications of the invention of art, so that he returns to Jakobson's lecture critiquing modern linguistics, semiotics and poetics, where Jakobson demonstrated differences between factual and imputed relations between signifiers and what they signify (p. 143) identifying, in the process, the missing term, the sign type that indicates relationships of "imputed similarity" or artifice. A term used by Jakobson corresponding to what Preziosi (2003) refers to as "ostensification" (p. 144) or the ostensible, what is presented as being true, or appearing to be true, but usually hiding a different motive or meaning. Characterizing this mode of practice as something at odds with modern practice, and more in line with medieval and ancient times, Preziosi (2003) returns to "Aristotle's Nicomachean Ethics, in which there exists a representational relationship between words and things, or, as the scholastic dictum put it, veritas est adaequatio verbi et rei (where res can mean not only thing or object but thought, feeling, or opinion)." (p. 145) Adequation as a relational term hints at movement back and forth from what is being fit to, and expression of truth in words or things is always this kind of adaequatio or approximation, a tending toward, an as-if. Thus this is not a "representation" as such, but a movement towards something. Preziosi (2003) writes:

An iconic sign relationship (all these terms refer to relationships between things, not kinds of things) is primarily one of factual or literal similarity; an artifice(i)al sign is one of imputed similarity, of adequation rather than equality... I have been drawn to this notion of artifice in no small measure because it allows us to deal with the extraordinary complexities - the fluid and open-ended relativities- of visual meaning in a clear yet nonreductive manner (p. 146).

The notion of artifice may serve as "the locus of working on memory and meaning as processes of adequation" (p. 147) asking us to see artworks not as "representations" but rather as questions soliciting our engagement pedagogically (p.147).

\section{Has Anyone Seen the Field?}

In his treatise concerning images, Göran Sonesson (2003) similarly comments, "it still seems impossible to establish a consensus among all semioticians on what semiotics is all about; and many semioticians (including the group $\mu$ ) will not even care to define their discipline" (p. 3). Perhaps we can begin from a premise of understanding semiotics as simply the study of signs, but what signs might be defined as is also widely debated. For example, Susan Petrilli and Augusto Ponzio (2005), begin their book, Semiotics Unbounded by considering what the boundaries of semiotics might be, and decide these bounds depend on the object of study, signs. However, "What signs are, and where they are, depends on the model of sign at hand" (p. xvii). Their approach opens the possibility of allowing the objects to inform the models, and the models to then define the terminology as it is used; in other words, they sidestep the definitional stage by stating simply "it depends". Despite developments, few scholars today would disagree with St. Augustine's claim: "all instruction is either about things or about signs; but things are learnt by means of signs" (Omnis doctrinal vel rerum est vel signorum, sed res per signa discuntur) (Augustine De doctr. chr. I 1, 1963, p. 9 in Stanford Encyclopaedia of Philosophy, 2.1). . Mieke Bal and Norman Bryson (along with Michael O'Toole and the Australian school) defend a useful side to the lack of disciplinary status of semiotics because it, 
... offers a theory and a set of analytic tools that are not bound to a particular object domain...[and] lends itself to interdisciplinary analyses, for example, of word and image relations, which seek to avoid both the erection of hierarchies and the eclectic...Considering images as signs, semiotics sheds a particular light on them, focusing on the production of meaning in society... (p. 176).

Since I am concerned with the workings and offspring of a specific photograph and how different people have taken and used it, this particular perspective at first seems promising. Sonesson (2003) observes that the point of view of semiotics "is to study the point of view itself" or "it is mediation, i.e. the fact of other things being presented to us in an indirect way" (cf. Parmentier 1985).

What semiotics, regardless of its "name" or category, gives me is a specific language parcelled out between the works of various theorists (in Europe and beyond) who struggle with the various conundrums inherent in the art (or science?) of it. In a nutshell, "semiotics is concerned with everything that can be taken as a sign" (Eco 1976, p. 7). Semiotics involves the study not only of what we refer to as 'signs' in everyday speech, but also of anything that "stands for" something else. In a semiotic sense, signs take the form of words, images, sounds, gestures and objects. Contemporary semioticians study signs not in isolation but as part of semiotic "sign systems" (such as a medium or genre). They study how meanings are made. By making more explicit the codes by which signs are interpreted we may perform the valuable semiotic function of denaturalizing signs. Deconstructing and contesting the realities of signs can reveal which meanings are privileged and which are suppressed. To decline such a study is to leave to others the control of the world of meanings that we inhabit. Sonesson (2003) concludes: "Semiotics, I will contend, is not about what something means; it is about how it means" (p. 30). His emphasis is on a processual model rather than an irretrievably reductive explicatory one. The same object can mean something in one context, and nothing in another, so that is it not a "what" question but more of a "when" and "how."

Umberto Eco, beginning with Trattato di semiotica generale (1975), "contributed significantly to the encounter between Saussurean 'semiology' and Peircean 'semiotics'" (Petrilli and Ponzio 2005, p. 310). It is worth taking a closer look.

\section{I hear an Eco}

Eco prefaces Semiotics and the philosophy of language by declaring his main purpose is to show that:

The sign is the origin of the semiosic processes, and there is no opposition between the 'nomadism' of semiosis (and of interpretive activity) and the alleged stiffness and immobility of the sign. The concept of sign must be disentangled from its trivial identification with the idea of coded equivalence and identity; the semiosic process of interpretation is present at the very core of the concept of sign (p. 1). 
He thus directs our focus toward interpretive processes and away from reductive notions of messages to be decoded. Throughout this work, Eco reviews semiotic theoretical problems by examining the concepts: sign, meaning, metaphor, and symbol with reference to the historical development of the sign model. He writes, "semiotics initially emerged as reflection on the sign; but subsequently this concept was gradually put in crisis and dissolved, and interest shifted to the engendering of texts, their interpretation, the drift of interpretations..." (1984, pp. xiv-xv). Eco (1984) stresses the need to recover earlier notions of the sign as dynamic semiosis (action involving tri-relative cooperation of representamen, object, and interpretant) and not a code to be deciphered with its built-in assumption of fixed correlations. However, some concepts, according to Susan Petrilli and Augusto Ponzio's (2005) critique in Semiotics Unbounded, are not directly dealt with in Eco's approach. The most significant one of these, and one they believe must be developed, is "the dialogical character of the sign and its essential otherness or alterity. As clearly emerges in Peirce's formulation, interpretation semiotics calls for this type of development" (p. 325).

Overall, a useful conceptualization Eco provides us with is the careful differentiation he makes between general (or theoretical) semiotics and specific (or applied) semiotics. What he terms general semiotics deals primarily with the philosophical questions, while the specific variants of semiotics are divided by technique or method of application, and how they deploy terminology in order to study their respective objects whether they be narratives, textual discourse, objects, artefacts, behaviours and so on. He describes specific semiotics as one that "aims at being the "grammar" of a particular sign system, and proves to be successful insofar as it describes a given field of communicative phenomena as ruled by a system of signification" (p. 5). Additionally for Eco (1984), "these systems can be studied from a syntactic, a semantic, or a pragmatic point of view" (p. 5).

Eco (1984) asserts: "every specific semiotics is concerned with general epistemological problems. It has to posit its own theoretical object ... and the researcher must be aware of the underlying philosophical assumptions that influence its choice and its criteria for relevance" (p. 5). He does not elaborate extensively on specific semiotics except to note that each needs to take into account the ambiguities of the sign system in question and that the objects are usually "stable" that is, they enable researchers to understand which expressions are "produced according to the rules of a given system of signification, are acceptable or 'grammatical' and which ones a user of the system would presumably produce in a given situation" (p. 5). Eco describes the contributions of specific semiotics as direct impacts on society giving the example of how a study on the internal logic of road signals can help municipalities in improving the practices of marking roads. However, his central thrust is to differentiate the task and nature of general semiotics from the specific. The basic problem of general semiotics is philosophical, and is addressed through three different questions:

(a) Can one approach many, and apparently different phenomena as if they were all phenomena of signification and/or of communication?

(b) Is there a unified approach able to account for all these semiotic phenomena as if they were based on the same system of rules (the notion of system not being a mere analogical one)?

(c) Is this approach a "scientific" one? (p. 7)

These broad questions parallel the ones I have often asked myself regarding the famous Korda image of Che. The object of study is the concept of sign itself insofar as it can explain a series of behaviours 
"be they vocal, visual, termic, gestural, or other" (p. 7). What this philosophy provides is explanatory power for what might otherwise be disconnected data. In other words, it provides coherence, one that may not be sustainable outside the framework of the philosophical assumptions but nevertheless provides a way for considering things as a whole.

Eco sets up the debate in a way that allows him to move us toward recognizing that the essential matrix is between presence and absence, referring to Derrida but also Leibniz. Essentially, a sign must stand for something outside itself: it paradoxically presents an absence, but the presentation itself contains an absence as well. As expressed by Petrilli and Ponzio (2005), meaning "is inseparable from the work of translation carried out through the processes of interpretation, to the point that we can state that signs do not exist without another sign acting as a translatant sign" (p. 302). The structure that general semiotics is concerned with tracing is that of the "inference which generates interpretation" (p. 38) so that understanding a sign is not only a process of recognition but also always interpretation.

The understanding of a sign is always already contextually bound as was recognized by semiotic theorists breaking from structuralism. Kent Grayson (1998) writes, "When we speak of an icon, an index or a symbol, we are not referring to objective qualities of the sign itself, but to a viewer's experience of the sign" (in Chandler 2002, p. 29). This explains why the image of Che can in some cases be a symbol, and in others an icon or simply an index as the first original photograph was to its photographer. Signs may also shift over time. But we are not looking at a closed system since a sign, finally, does not denote its own meaning. So that, "To know that 'water' means the same as $\mathrm{H}_{2} \mathrm{O}$ and that $\mathrm{H}_{2} \mathrm{O}$ means the same as 'acqua,' and so on, without knowing what these terms refer to, is not enough for them to function as signs" (Petrilli and Ponzio 2005, p. 318).

The metaphor of the encyclopaedia illuminates and allows us to approach what Eco (1984) is theorizing. The encyclopaedia represents something that has no centre, we are always somewhere in the middle of a labyrinth made up of a network of interpretants that is virtually infinite because "a given expression can be interpreted as many times, and in as many ways, as it has been actually interpreted in a given cultural framework; it is infinite because every discourse about the encyclopedia casts in doubts the previous structure of the encyclopedia itself" and "it does not register only "truths' but, rather, what has been said about the truth or what has been believed to be true as well as what has been believed to be false or imaginary or legendary, [imputed] provided that a given culture had elaborated some discourse about some subject matter" (p. 86). In this context, interpretation becomes a matter of hypothesis where one can posit a local description of the net or labyrinth, but it will necessarily result in a myopic vision as no one can see "the global vision of all [the labyrinth's] possibilities" (p. 83) from their particular node. Understanding the work of semiotics as interpretation rather than decoding can account for the "irreducibly other as theorized by Bakhtin and by such philosophers as Emmanuel Levinas" (Petrilli and Ponzio 2005, p.327). Peirce signals this essential interconnectedness through a relation of otherness "as being present in all signs when he says that their interpretants are somehow always other than themselves" (Petrilli and Ponzio 2005 p. 339). Eco, with others such as Peirce and Bakhtin, agree it is not the sign itself that functions as a container of meaning, rather meaning exists in the relations among signs. What is the significance of these ideas with respect to the visual? 


\section{Jakobson's fourth sign-type: Artifice}

Jakobson proposed a fourth type of sign, the artifice, to address the relationship of "a message which signifies itself, [and] is indissolubly linked with the esthetic function of sign systems" (Jakobson 1968:704-705, in Allingham, p. 2008 p. 171-2). Despite Jakobson's uneasy relationship with C.S. Peirce's work, it seems to be a productive option that would not neglect intention, expressivity, and affect.

This fourth type resonates with some of Umberto Eco's ideas. For Eco, comprehending what they stand in for as icons is not as important as "recognizing a content 'other' for which the represented object stands" (p. 17). They are also called symbols "but in a sense opposite to that adopted for formulas and diagrams. Whereas the latter are quite empty, open to any meaning, the former are quite full, filled with multiple but definite meanings" (p. 17). Luckily, he does not avoid the ambiguities and inextricable overlaps between these categories. Consequently, Eco writes: "The nature of the sign is to be found in the 'wound' or 'opening' or 'divarication' which constitutes it and annuls it at the same time"(p. 23). I conceive of the nature of the sign type Jakobson put forward just such a 'wound' or 'open' type sign in that, as artifice, it ceases to be once it is recognized as such, while yet being, simultaneously providing a multiple beyond. Artifice is in a sense designed to be pierced, it is the only self-conscious sign type and the only sign type whose intention is to represent something other or something more than what it seems to. Like disguise, once it is seen-through it ceases to disguise it ceases to act in that way. Yet, we can still derive pleasure and an aesthetic knowing from seeing and seeing through the disguise. It is artful and beautiful. And we can move in an oscillatory motion in the seeing/knowing. I contend that the aesthetic is part of the meaning content of a sign but that not any sign-type will do.

The renderings of Che's image are always the same image, or topic, but being reproduced in limitlessly varied media, contexts, and figurations. There is structure and yet it is open, I propose that the format of the four sign types is similar in many ways. The fourth position, which Greimas regarded as explosive, is occupied by artifice, which is a modality that splinters like a fractal into multitudinous possibilities. It is real, but virtual, in the sense that it is actual and possible at the same time depending on when/if it is recognized. Thus though related to a structure, it is fluid. Such a relation allows us to see the structure as something artificial that allows us to look at form through abstraction but does not generalize, or reduce it.

Donald Preziosi (2003) says artifice "allows us to deal with the extraordinary complexities the fluid and open-ended relativities- of visual meaning in a clear yet nonreductive manner (p. 146). In short, artifice might be a conceptual tool to face kind of challenge posed by the image of Che Guevara in being fluid, open-ended, and irreducibly complex. Like Eco, Preziosi (2003) is clear the sign is "a relationship between things (of any kind)." (p. 31, my emphasis) Preziosi's (2003) pivotal observation is that Jakobson demonstrated the differences and importance of "'factual' and 'imputed' (or conventional/virtual) relations between signifiers and what they signify.” (p. 143)

Thus, Preziosi (2003) pairs up the notions of artifice and ostensification to show the relation is "presented as being true or appearing to be true, but usually hiding a different motive or meaning." (p. 144) He also links it to the Aristotelian adaequatio, or adequation, or "fitting," "adjustment" (p. 145). In this sense the artifice is an invitation to imagine otherwise. What is the final fit that cannot quite be represented? 
The notion of artifice requires a necessarily participatory relation. This allows us to understand how "artworks are questions posed and adequations mooted, soliciting engagement so we may learn to see." (Preziosi, D. 2003 p. 147) It is a pedagogical relation at the core not only of ostentation or adequation but of presentation and a pointing to something that one can only coconstruct. It is a double motion because in a way the artifice is telling us that it is pointing to something and not pointing to it at the same time, but being, inhabiting or embodying, it in some way that can only emerge when we catch on. Additionally, artifice tends to point at its own constructedness. Because only this sign type emphasizes and exemplifies human skill in doing something, as such it stretches into the realms of finesse or cleverness, as well as intention something that none of the other sign types incorporate. But this is also what makes it delightful and effective, we are always negotiating artific/ial signs in our daily lives, and we are more skilled at it than we imagine ourselves to be.

Preziosi delineates the difference between the icon and the artifice: "An iconic sign relationship is primarily one of factual or literal similarity; an artific(i)al sign is one of imputed similarity, of adequation rather than equality" (2003 p. 146). I would further explain by differentiating from the relationship that a symbol has as a sign. A symbol's relationship to the signified is more or less arbitrary and not necessarily similar to imputed similarity.

As Preziosi (2003) noted: "The truth - the veritas - in words or things is always one of adaequatio or approximation or a tending toward, an as if." (p. 145) A metaphorical relation means one object is understood in terms of another, but is more complex than the merely substitutional. One of the key words in understanding this semiotic mode should be "parallelism" but also the notion of the virtual.

At the close of 2008 both Peter Allingham and M. J. Sidnell published works addressing artifice. Both are worth looking at. Allingham (2008) adds: "Metonymic presentation works through design, layout and, e.g. the signatures of brands and logos. These space types catalyse experiential selection and creative interactive behaviour through, e.g. branded space (cf. Höger 2004)." (174) There seems to be an overlay of metonymy and metaphor to produce the artifice. But I would reverse the statement: "Metonymic presentation works through design," to read, "Design works through, among other things, metonymic presentation" because we need to acknowledge the creative role of design as something that can invent new connections. The metonymic is perhaps one technique in an entire constellation of possibilities within the creation process of artifice. I am hesitant to give it a leading role. Having said this, it is easy to recognize the images of Che that do not even remotely endeavor to gesture towards the man because they are being used to represent attributes such as rebellion. This is a symbolic move, and I wish to differentiate it from artifice.

Finally, Allingham (2008) turns to Preziosi to observe the four kinds of semiosis afforded by the four types and remark on the ability of artifice to: "represent by presenting, by showing, producing, which is why artifice or presentation must be on, or simply be the limit of representation, i.e. the aesthetic form or expression that captures and engages the human senses before any cognitive processing or understanding takes place.” (Cf. Preziosi 2003:137ff in Allingham, P. 2008 p. 173) Artifice seems to be about to slip off the map of semiotics.

Allingham's (2008) critical observations lead to two very useful insights: first, "it seems that Peirce's typology of signs is insufficient when it comes to dealing with the expressivity of these objects." (p. 171-2: my emphasis) In observing the expressivity of objects, I contend that Allingham is looking at their virtual qualities. I see a clear link between what artifice is able to do, the notion of expressivity, and the virtual. Expressivity must be addressed, and would say that only artifice can do 
so.

Secondly, Allingham (2008) introduces the idea of liminality with respect to artifice. Again he is actually dealing with the real of the virtual. He writes: "In the quadrant of metaphoric presentation, physical space tends to be virtual, i.e. being established through aesthetic means for the sake of pleasure or growth" (p. 175). So the space for the event is real but virtual, and aesthetic means are the vehicle for creating it. This space is extremely productive because it provides an alternate place where one can be free to think differently from how one is colonized to think in everyday life. Allingham (2008) recognizes not only that the physical space tends to be virtual in the $4^{\text {th }}$ quadrant, but also that this is a volatile and about-to-be-destabilized, or in his words: "a semiotic mode that is liminal, interfacial, as it represents through presentation" (p. 177). In being liminal it is at the edge of the relationship of representation common to other sign-types in that it is always-about-to-become something else. It teeters on the edge of unpredictability.

Sidnell, (2008) rightly observes that, "Jakobson may have designated artifice a distinct mode rather than a kind of symbol, within the Peircean triad, in order to make the 'artistic character' distinctive at the modal level. (p. 18) But he critiques Eco for not offering a semiotic understanding of beauty in his broad survey in History of Beauty (2004). Something that, for Sidnell, is critical to a concept of semiotic praxis. Indeed Sidnell seems to stop dead with the remark: "With this Beauty, semiotics, intriguingly, has nothing at all to do... In a very wide-ranging survey, he [Eco] has seen no need to broach the issues of whether a sign may be beautiful, insofar as it is a sign; and whether beauty as such be a sign." (Sidnell, M. J. 2008, p. 23) For me this is the critical opening where artifice and by extension the virtual enter the dialogue.

\section{Exploring artifice: The semiotic black market ${ }^{i i}$}

"The discussion over the primacy of art or nature - does art imitate nature or does natural beauty imitate art? - fails to recognize the simultanaeity of truth and image...it is the very structure of the sensible as such. The sensible is being insofar as it resembles itself"

(Levinas 1987, 7-8)

C.S. Peirce's basic sign theory provides for three basic relationships between signified and signifier, icon (based in resemblance), index (based in causality), and symbol (based in convention). As we have seen, Jakobson proposed artifice as the fourth main to show a $4^{\text {th }}$ relationship not accounted for by the index, icon, symbol triad. Peirce's initial distinction among three relations between signans and signatum, (Peirce 1931:1.558) is:

1. -An indexical relation based on factual contiguity;

2. -An iconic relation based on factual similarity;

3. -A symbolic relation based on imputed contiguity. 
Jakobson wrote:

[The] interplay of the two dichotomies - contiguity/similarity and factual/imputed — admits a fourth possibility, namely, imputed similarity.

And so the table looks like this:

\begin{tabular}{|l|l|l|}
\hline & contiguity & Similarity \\
\hline factual & index & Icon \\
\hline imputed & symbol & Artifice \\
\hline
\end{tabular}

In other words, something can be said to be artifice when it is done in an ostensible manner. Something created by artifice is said to be "effectively" real.

Something can be said to be artifice when it is done in an ostensible manner - avowedly, declaredly, professedly. Something created by artifice is said to be "effectively" real. Artifice is usually distinguished from, and often implicitly or explicitly opposed to, actually or really: in other words something that is apparently, but not necessarily or really. ${ }^{\text {iii }}$ We can say that artifice is a selfconscious sign. At the core of my understanding of artifice as the fourth sign-type is the idea that it is performative, in the sense that it "brings about" the allegorical connections as well as presents mimetically the structure of the sensible. The idea of the structure of the sensible ${ }^{\text {iv }}$ is something that Rancière takes up and applies to both politics and aesthetics which links it back to what he says about changing the world when you interpret it. If we have more nuanced ways of interpreting the world, we can have new shades and tones to our understandings, which in turn enable us to act in new and perhaps more powerful ways. In other words, if we can see how some representations are not simply what they appear to be but at the same time are other things, without losing whatever it is they apparently had, it means we don't have to categorize them as one thing only, it allows for more fluidity and possibility. We can connect this idea to what Peirce writes about experience being our only teacher as cited by Portis-Winner; "its action takes place by a series of surprises, bringing about a double consciousness at once of an ego and a non-ego directly acting upon each other" (CP 5.53) (Portis-Winner, I. 1999, 29). The pedagogical moment of a sign exists only at the moment of its making or becoming in the recognition by the viewer or interpretant. Learning always already works through virtual levels and through our ability to comprehend artifice. The masking of the object in order to speak to it more directly is how we can see this functioning. Therefore the role of intention is central, as are the parts played by guise and disguise, gaps and misrecognition. The sign that effectually disappears as soon as you recognize it is disguise. Yet it is no less really representing what it purportedly represented in the first place.

The artifice as a sign type and the specific relation it bears to the signified can be better understood if we keep in mind the idea of having a duplicity of awareness to better grasp the quasipresence and imminent visibility of the oscillating imaginary. We can understand artifice as an 
ignescent sign, one that is capable of bursting into flame at the moment of recognition, the moment one recognizes it as an as-if, and as also not-that-but-other.

\section{From artifice to the virtual via parallelism: Enter Gell}

Artifice, can aesthetically impute similarity through aesthetic means and so it becomes an "as if" in a relationship that can be characterized as a parallelism. Thus, artifice is an actualization of the virtual (relationship). For Jakobson, following Hopkins, the principle of parallelism does not connote identity but rather correspondence through either points of similarity or contrast. The artifice is virtual (because what we 'see' is other than what we are being shown, though we also see that) and intrinsically ambiguous, while it represents through a parallelism, represents by showing something that it is not to talk about the thing that it is. In other words, aesthetically an artifice is what it is not, and thus seeks its meaning in unlikeness by triggering the viewer's recognition through visual cues and thus embodies a different relationship with the signified that an icon, index or symbol. At this point Gell (1998) reminds us that: "some 'representations' are very schematic but only very few visual features of the entity being depicted need to be present in order to motivate abductions from the index... Recognition on the basis of very underspecified clues is a well-explored part of the process of visual perception. Under-specified is not the same as 'not specified at all' or 'purely

conventional'."(25) We can see this in many of the instances when Che Guevara's image is little more than a silhouette. Jakobson saw parallelism as equivalence rather than identity; the equivalent pairs are, in turn, juxtaposed according to the principle of similarity or contrast. ${ }^{\mathrm{v}}$ (p. 6) In order to move on, we need to keep in mind such things as Merleau-Ponty's "duplicity of awareness" and Foucault's (1968) discussion of Magritte's painting C'eci n'est pas une pipe as a calligram that inaugurates a play of transferences that run, proliferate, propagate and correspond." (p. 49)

At times I have referred to the term virtual. My use and understanding of this concept is built on four separate but interrelated developments of "virtual" by Peirce, Shields, Rancière, and DidiHuberman. I will briefly explain each of these approaches to the concept, while noting that they do not necessarily contradict each other. The virtual is key to understanding the workings of imputed signs. "The dictionary definition of "virtual" was penned by none other than Charles Sanders Peirce." (Skagestad, P. p. 2) For Levinson, "Peirce defines a "virtual" $X$ as what you get when the information structure of X is detached from its physical structure" (Skagestad, P. Peirce, Virtuality, and Semiotic, p. 2$)^{\mathrm{vi}}$.

In a four part ontological frame, Shields positions the virtual as "real without being actual, ideal without being abstract" (25) pairs it with the concrete as the other part of the axis of the real. He follows Deleuze in seeing the opposite of the really existing as the possible: "The possible is never real, even though it may be actual; however, while the virtual may not be actual, it is nonetheless real" (Shields, 25) vii.

The sign-type of artifice is functioning as an "as-if"? Bergson writes "the virtual image evolves toward the virtual sensation and the virtual sensation toward real movement: this movement, in realizing itself, realizes both the sensation of which it might have been the natural continuation and the image" (Bergson, 1988: 131 in Shields, 26-7). There is a duplicity here a double movement that fits nicely with artifice. Our experience of the aesthetic object necessarily authenticates a perception of the world beyond the senses through the authenticity of the virtual. Thus we can say that an object 
happens, that is, it enters into experience. Artifice is purportedly one thing, while it also is virtually another, it is the trickster's favorite. The Trojan horse for example was a gift and at the very same time a weapon.

For Rancière, the artifice is first and foremost a political sign mode. In On the shores of Politics he looks at what both Plato and Aristotle think democracy is and compares them. He writes: “...in Book IV of the Politics where Aristotle proposes that there should appear to be elements of both types of regime (oligarchy and democracy) and yet at the same time of neither, a good polity being one in which the oligarch sees oligarchy and the democrat democracy (p. 42 my emphasis). How is it that one group can see one thing and another sees something completely different? We know the oligarchs are controlling the "appearance" of the regime to suit themselves and to manipulate the democrats. There is an art to making something look like something it is not quite, it is an "as-if" redistribution of the sensible, in a word-- artifice.

Rancière continues and directly links to the notion of artifice: "It is worth pausing to consider the function of artifice here, for it embodies all the complexity of Aristotle's conception of politics" (42-3). He sees Aristotle considering politics "not as illusion or machination but as the art of life in common" (43). Artifice is the principle whereby people play each other's games and it is not simply reducible to being cunning. The space of shared meaning that makes legal words effective is for Rancière, a virtual space. He emphasizes: "Those who take the virtual for the illusory disarm themselves just like those who take the community of sharing for a community of consensus" (p. 50).

Finally, in a fourth variation Georges Didi-Huberman (2005) elaborates his theory of visual figuration by distinguishing between what he calls the visual, the visible, and the virtual. In his triad, the visible equals what we can see, the visual indicates something that cannot be seen (for example in Botticelli's Birth of Venus her hair seems to be blowing in the wind as she arrives on her shell, the wind itself [indicated by the hair but unseen], is the visual), and the virtual is a presentation of something unrepresentable. Using Fra Angelico's painting of the Annunciation, as his primary exemplar, Didi-Huberman takes the whiteness of the walls and the blank paged book in the Virgin's hand to illustrate the virtual. He writes: "The whiteness is so simple, yes. But it is so altogether like the blank inside of the little book held by the Virgin: which is to say that it has no need of legibility to carry an entire mystery of the Scriptures" (22) Thus, "Fra Angelico simply used the presentation of the white - the pictorial modality of its presence here in the fresco - to 'incarnate' on his level something of the unrepresentable" (24). In this way the white paint, while being white paint, is also an act and an acting of whiteness, the uninscribed, the blank, the yet-to-be-but-promised, an event in the making, and all that it would have been for Fra Angelico. His conceptualization of the virtual resonates strongly with the performative aspect of artifice I underlined earlier. These four conceptualizations of the virtual, are compatible yet different elaborations of how the virtual can be described. Without ignoring the multiple trajectories and nuances in the concept, I will understand the virtual as real but not concrete, noticeable but not visible, recognizable through its effects, impact, or actions/incarnations designating its information structure. In the second part, I move to an engagement of salient concepts and application in a concrete example. 


\section{PART 2: THE CASE OF KORDA'S CHE IN EAST TIMOR}

“In the beginning was the eye, not the word.” (Otto Pächt, 1995)

\section{Introduction}

I started with traditional semiotics as a ground from which to approach the dialogic nature of the sign and its alterity; it's essential woundedness simultaneously constituting and annulling it; its ability to register divergent relationships between signified and signifier; its coherence contingent on the framework; its insufficiency when it comes to the expressivity of objects; and its failure to address the art of dissemblance directly. I also found that these limitations with respect to affect and the world of movement and fluidity could be responded to through some of the work done by Roman Jakobson, and later Donald Preziosi on the notion of artifice. Some useful aspects of this notion relate to the possibilities provided by the "as-if" or the enveloping of the virtual, in the nature of artifice achieved through multiple coding and other tactics that appear as a general strategy of parallelism and the way one was able to interpret these events seemed to happen through abduction.

When a viewer recognizes the virtual (and invisible) qualities of visible image (of Che Guevara), the possibility of the agency of the art or artifact is created, and thereby the efficacy of the virtual. I am going to develop this theory through an example. By looking at how the image of Che Guevara has mobilized in East Timor, I will link artifice with parallelism and the virtual to show how the virtual is efficacious in allowing an image to become a social agent. I chose to look at this particular part of the world because I was somewhat startled at the magnitude of the image's presence and impact in a place so geographically distant from where Guevara himself was active.

As a way to tie semiotics and the notions of the virtual and artifice with visual images, my approach draws on some of Alfred Gell's (1998) principles from Art and Agency. With Gell, I agree most "literature about 'art' is actually about representation," (25) and thus sidelines the performative and agentic aspects of objects, something the social semiotic approach fails to fully appreciate. Second, I would accept Gell's definition of art as "a system of action, intended to change the world" (p. 6) and thus the emphasis is clearly on "agency, intention, causation, result \& transformation" (p. 6) rather than mere symbolic communication. To ground his theory, Gell (1998) uniquely expands the notion of index far beyond traditional semiotics by re-framing the notion of cause. He posits that an artist is the 'cause' of a work of art in the same way as fire is (usually) the cause of smoke. But smoke does not always mean there is a fire, and a smile does not always mean there is a happy friendly person behind it, thus Gell (1998) problematically insists that art does not ALWAYS function semiotically. However, I think it possible to see more nuanced semiotic function by expanding the notion of semiotics to include a kind of semiotics of the virtual, although it is more accurately understood as a kind of an anti semiotics because it is not direct representation being evoked, rather 
active presentation. Although broader, this tactic would still exclude the issue of expressivity. Gell's technique is limited by his failure to address intention in his expanded approach to index as the key difference in how "cause" comes to be vis-à-vis the traditional formulation. This intention is key to the notion of artifice because the similarity or link between signified and signifier is an imputed one, the sign is operating primarily on the level of the virtual.

\section{Che Guevara appears}

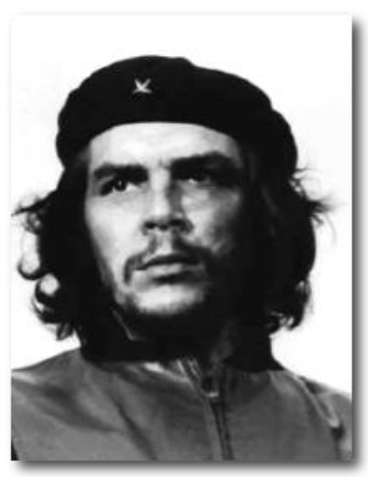

Another day, I head out of Dili towards the rugged hills that fracture the countryside. The trip takes a little longer than expected, as the road is a graveyard for careless drivers, twisting and turning upon itself like an itchy snake. My own vehicle is merely run off the road by a bus and later suffers a blowout... Other requisite stops include photo opportunities, stops to ask directions, and the obligatory gape-break, when the totally amazing presents itself - such as a warrior-clad cowboy with Che Guevara medals on his chest, riding a pony along the roadside. In this region, altitude means attitude.

(Graham Simmons, 2009)

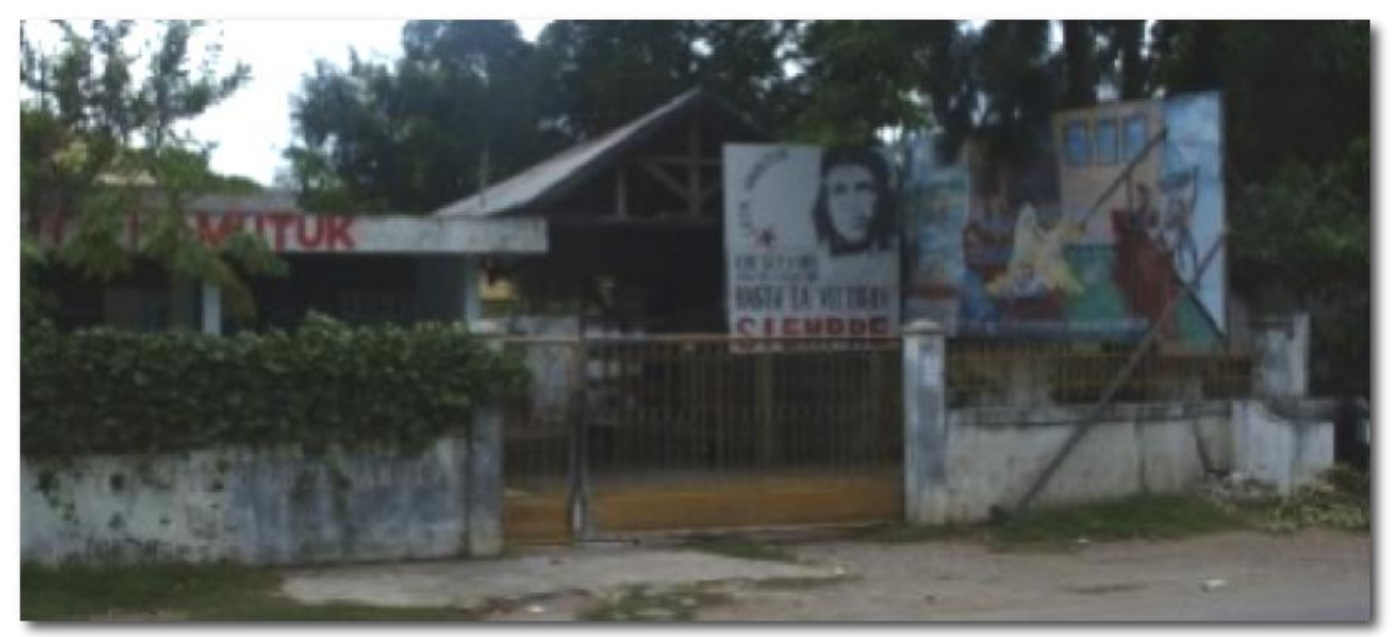

On the blog, East Timor - I was there before it became big I came across this photo (below) taken in Dili. It was entitled $C$ e as a simple indication of the subject. There Guevara's face appears in two-tone on the billboard within an unknown building's enclosure. What is the image doing so far from home? I would venture it is acting and thus performative in the sense that it: demarcates, announces, and protects to some extent that territory while interpolating those who resonate with that particular image. It is accompanied by one of the usual slogans "Hasta la victoria siempre" as well as other words too blurred to decipher. 
Abutting the mural/billboard is another one depicting a room with three windows and a figure speaking at a podium with some kind of lamp or microphone being held on a rod extending towards him. Yet this more involved depiction is completely disregarded and made ambiguous by the puzzled photographer/blogger Daniel Gerber who writes beneath the photo: "Che Guevara seems to be really popular here, I don't know why." Clearly, the image does not speak to everyone.

Indeed my brief Internet searches seemed to confirm the popularity of Guevara's image in East Timor as it quickly revealed a number of references to, and images of the revolutionary guerrilla fighter; for example this mural where the two

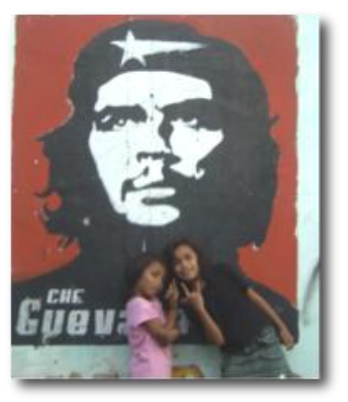
girls are posing for the shot, in St. Crus, Dili (Flickr, franjer79).

The far right photo can be seen as a riff on the famous Korda image where the artist has Che with the cigar to his mouth, but retains the frame with the hair and beret, taken in Baucau, East Timor (J. Patrick Fischer, 2002) called Wall painting of Che though a definite wall is not apparent. I did read that when travel writer Norman Lewis visited Baucau in 1991, he described the city as "one of the most disturbing places in the world... a disheveled town full of barracks and interrogation centres with high, windowless walls and electrified fences. Baucau had been the end of the road for so many real and assumed supporters of Fretilin:" (Simmons, G. 2009) A suitable place for Che's image?

Why is the image of Che in East Timor? Why at this time? Why this particular

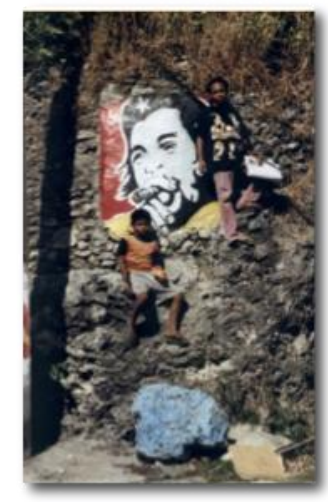
figuration?

\section{Background/Context}

The tiny half-island a thousand miles from nowhere of approximately 850,000 people speaking languages Tetun, Portuguese, and Bahasa Indonesian seems irrelevant to global business or power politics. (Rogers, B. 2002) After 455 years, the Portuguese abruptly abandoned this colony in 1975. Merely nine days after East Timor declared independence; Indonesia invaded and installed a genocidal regime. "The thought of East Timor falling into the hands of Che Guevara look-alikes horrified Henry Kissinger, and so he gave Suharto the nod to invade. Australia, too, wanted to get its hands on the oil ..." (Rogers, B. 2002) Rogers' description of "Che Guevara look-alikes" made in hindsight is telling. It indicates something was happening in the East Timor of 1975, and indeed a resistance movement Fretilin (the Revolutionary Front for an

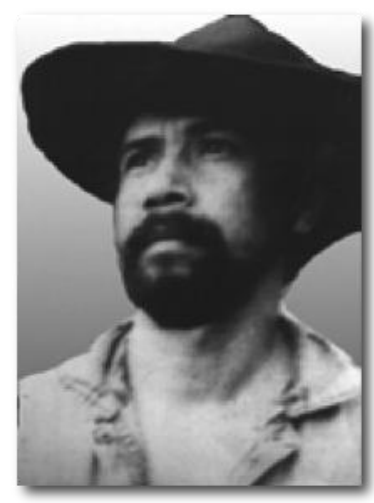
Independent East Timor) had been born, and an enigmatic leader, Xanana Gusmão had emerged. It also indicates a virtual link between a mental image of Che Guevara that somehow contaminates those who have similar ideals and are willing to act on those notions in terms of sovereignty or independence.

During the 24 years of Indonesian brutality, Xanana Gusmão and a handful of guerrilla fighters, who numbered no more than 160 at their peak, waged war against 22,000 Indonesian occupation troops in the island's dense jungles. In 1992, Gusmão was captured and imprisoned. "He 
quickly became one of the world's most prominent political prisoners, writing poetry and letters to keep the dream of independence alive. In 1997 Mandela visited and called for his release." (McCarthy, T. TIME Magazine Online 2000) In an article called Xanana Gusmão, el Che de la jungla, Luisa Futoransky (1999) recounts "They have frequently compared him to Che Guevara, Robin Hood, and Ho Chi Minh." Elsewhere he "was described by the press and analysts as a "poet-revolutionary" with the charisma of Argentine-Cuban guerrilla leader Ernesto "Che" Guevara, who had become an almost mythical icon of revolutionary struggles around the world." (de Queiroz, M. 2007)

From prison, Gusmão issued a challenge of a referendum on full independence for East Timor: "Whoever is afraid of a referendum is afraid of the truth." In 1999, Suharto's successor, B.J. Habibie, surprised everyone - particularly his own military - by taking up Gusmão's challenge.” (McCarthy, T. 2000 TIME Magazine) Again, the image of Che is noted in the press:

As the massive Indonesian ship left Jakarta, thousands of people filled its seven tiers. ... Among them were hundreds of East Timorese returning home to vote in the referendum. The majority were students, ... but there were also many refugees from the violence of antiindependence militias in East Timor. ... The clothes and luggage of those filling the decks were decorated with East Timorese and Falantiv ${ }^{\text {viii }}$ flags, independence slogans and pictures of Xanana Gusmão and sometimes Che Guevara. (King, S. 1999)

When Indonesia lost the vote, Indonesian-controlled militias butchered the Timorese and unleashed mass destruction causing the majority of the population to flee their homes in sheer terror. However less than a year later, TIME Magazine reported in 2000:

But something remarkable is happening on this half an island. Gusmão, 53, a former guerrilla leader and political prisoner, has tapped into reserves that are out of reach of the World Bank and the IMF, reserves of willpower and pride the people themselves barely knew existed. Exuding the authority of Nelson Mandela and the charisma of Che Guevara, Gusmão has been traveling the country spreading his vision of the future...

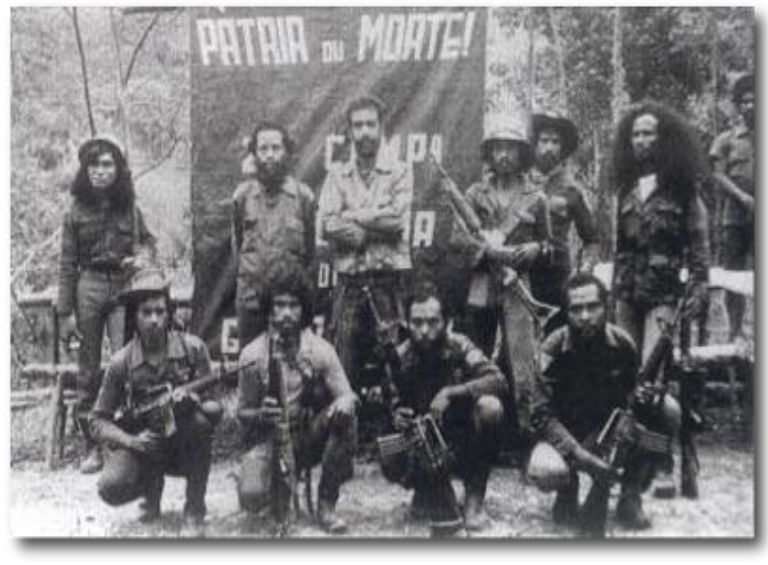

Clearly there is a striking political and ideological parallel between Gusmão and Guevara that is reiterated by mass media outlets but also pulses steadily at the grass roots level. And, in fact they fought the same enemy, for the same reasons, just in different times and places, and with different outcomes in terms of their own personal stories. The rebels demonstrate a self-conscious adoption of some aspects of the Korda image, as well as of the linked slogans, haunted by this famous matrix image. For example, in this old black and white photograph we see Xanana standing in the centre with some of his rebel troop and the banner with the phrase "Patria ou Morte" the Portuguese version of the famous cry by Fidel Castro on the fateful day in 1960 when the famous photograph of Che was taken. And there it stayed, stuck. Here there is a clear 
alliance with the revolution in Cuba which became, in Che's words: "the image of what is possible through revolutionary struggle, the hope of a better world... an image of what it is worth risking your life for, sacrificing yourself until death on the battlefields of all the continents of the earth..." (Guevara, E. "Lecture in Santa Clara" 1961 [my translation] online)

How can this old photo from East Timor somewhere in the jungle represent the Cuban revolution, its victory, and the Guevarist stance? Gell (1998) differentiates between modes of representing in a useful way: "The ideas of 'representing' (like a picture) and 'representing' (like an ambassador) are distinct, but none the less linked" (p. 98). The slogan on the banner is an index of Castro's words in a sense. The banner is there like a representative of the Cuban revolution, not iconic but an "artefactual body." (Perhaps one can say this mode of representing is indexical in that smoke can be seen as the ambassador of fire?)

The basis of the agency of an artifact is rooted in the notion of the distributed object or distributed person in the Maussian understanding of gifts as actual extensions of persons so that in a parallel way the reproduction of an image whether it is of an object or of another image is as-if a gift from that prototype. For instance, "Constable's picture of Salisbury cathedral is a part of Salisbury cathedral. It is, what we would call, a 'spin-off' of Salisbury cathedral." (p. 104) Similarly, every iteration of Che Guevara's face taken from the Korda photo can be seen as a spin-off. Consequently, if "appearances" of things are considered material parts of things, "then the kind of leverage which one obtains over a person or thing by having access to their image is comparable, or really identical to the leverage which can be obtained by having access to some physical part of them." (p. 105) This would explain many of the attacks on art works representing historical figures such as the 'slashing' of the Rokeby Venus by an angry Suffragette.

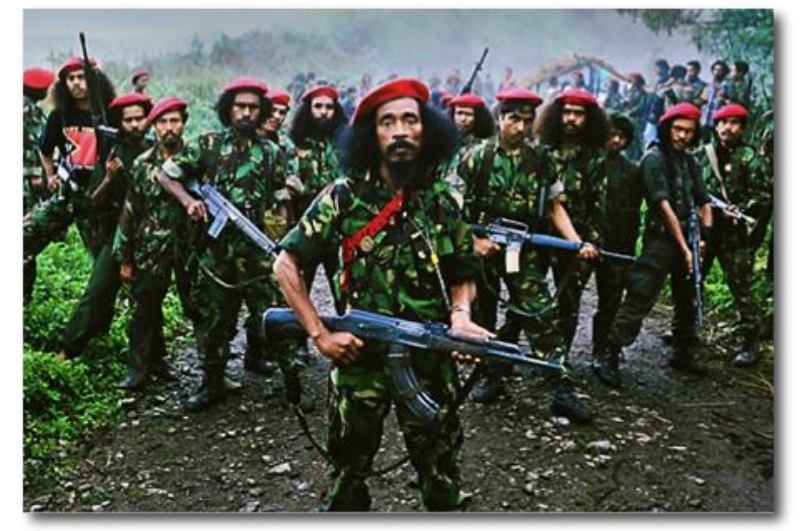

Even more dramatically evocative, is the color image, where there seems to be in direct conversation with Che's image; the hair-beret-facial hair combo is unmistakable for those familiar with the Korda photograph (though they have adopted red for the berets). Judging by how young Xanana looks, I would place it in the earlier years of their resistance. We can look at this photograph in more than one way. If we see it as the image entering into Xanana and his troop, then it is as-if a case of possession. The image (prototype) is an agent motivating the fighters (index) to take on its qualities both visible and virtual in a cause-effect relationship and we the viewers of the photograph are the recipients in a passive position but again motivated by our knowledge of the image to infer that it is the source of these fighters looking as they do, with the particular stance in preparation for the photograph.

We can also look at this photograph and see it as Xanana and his troop entering the image. In this case it would be as-if a dramatic performance where Korda the photographer would have the agency of a playwright in taking Che's photo which becomes the prototype represented by the actor (fighters) who actively index and are thus in an agentic position along with both the photographer and the image, in contrast to the audience (us) who witness the dots connecting through abduction. 
However, at the exact same time, we know this is neither a possession nor a play. We know this is East Timor and these fighters are revolutionaries in their own right. The image-inhabiting, or image-becoming is an artifice and the transformation, while visually signaled is virtual. However, it may serve to provoke fear in those who see these fighters or this photograph and remember the success of Guevara in the Cuban revolution. In this way it can be seen to be efficacious. The artifice is an actualization of the virtual (relationship) manifesting belief in victory for one: it is not actually Che Guevara, but through a parallelism, it is just as if it is!

In the student rally shown here, there is an emanation or leaking of the image onto one of the young supporters, who dons the beret as if to match the image: a black and white portrait of Xanana in profile. In a way I see it as Che's image in Xanana's image in and acting with this youth.

Finally, and at the root why I was compelled to write about East Timor, is this intriguing photograph taken supposedly in "Malibere village, East Timor" according to The Globalism Institute RMIT Report in 2004.

This institute based in Melbourne, Australia manages a number of research projects

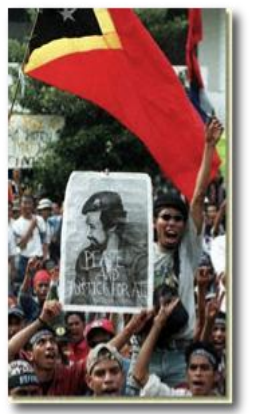
and one in particular under the umbrella of Sources of Insecurity focuses on East Timor: "social conflict in East Timor, violence, nationalism, social movements, globalization and global protest movements" and is supervised by Damian Grenfell. Oddly, nowhere else in the over 70-page document did another reference

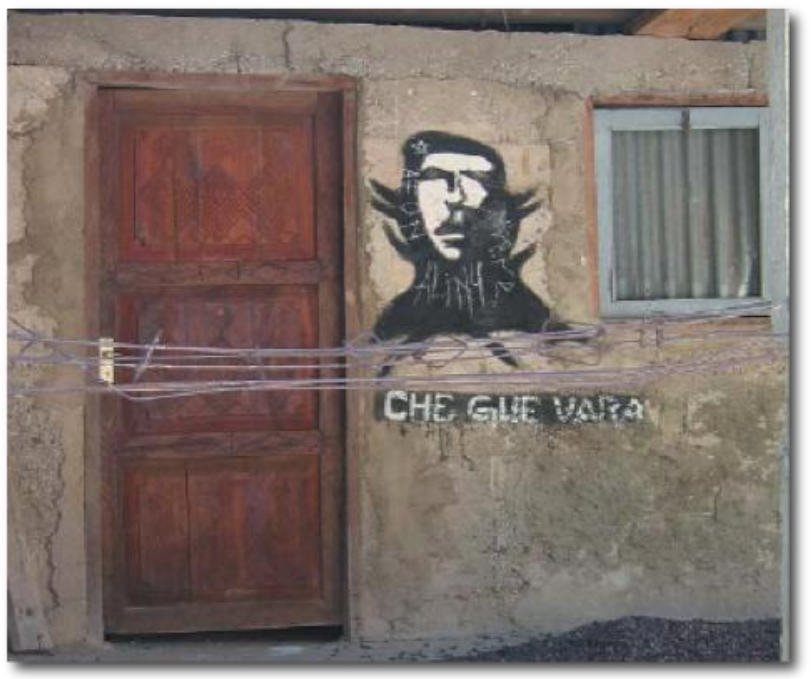
to this image, or an explanation of why it had occupied an entire page in the document appear. Neither was there another mention of Guevara outside the fascinating caption reading:

Che Guevara graffiti on Artorde de Araujo's house in Malibere village, East Timor, 2003. In part, because it was illegal to depict images of Xanana Gusmao, graffiti of other bearded revolutionaries was used as a sign of resistance"

If this caption is accurate in describing the situation, this is something of a reversal of the situation found in the color photograph of the rebels discussed above. This is an image clearly labeled "Che Guevara" but for those in the "know" it is really a virtual Xanana Gusmao. The image becomes the site where subordination is transformed into resistance through tactical conversions that allow what Sandoval (2000) calls a "dialectical movement of subjectivity that disallows, yes -but at the same time allows - individual expression, style, and personality." (p. 35) Che's image "is a congealed residue of performance and agency in object-form, through which access to other persons can be attained, and via which their agency can be communicated." (Gell, 1998, 68) The notion then, resonates with but goes beyond what Roland Barthes' had explored in his denotation (literal), connotation (socio-cultural, personal) approach to visual meaning. It does this because its tactic is one of disguise, and of imputed similarity, rather than a gesturing at different levels or orders of signification. Gusmao is invisible in the image, and yet it is an image of Gusmao, at the same time as being no less an image of Guevara. 
We can conceive of Gell's (1998) agency for an artwork/image as a "modality through which something affects something else" (p. 42) and is absolutely relational and context dependent (p. 22). So, given the necessary context, "whatever type of action a person may perform vis-à-vis another person may be performed also by a work of art, in the realms of imagination if not in reality." (p. 66) But we know that a more nuanced understanding of reality takes into account the real of the virtual yet not concrete realm. Because we recognize agency by its effects, only when someone acts as an agent can they become an agent and not before. They must "disturb the causal milieu in such a way as can only be attributed to their agency." (p. 20) An artifact is rarely a primary agent, but can act as a secondary agent. For example, when a child feeds a doll because it is hungry, the doll is a secondary agent to the degree that it is able to channel, or become a conduit for the primary agent's action. Similarly, "social relations only exist in so far as they are made manifest in actions." (p. 26)

We can say that the prototype Che Guevara appears as agent since we know the activities of the artist in that case were subordinate to prototype (Korda did not plan the original photo and in various interviews he speaks of it snapping itself when Che suddenly appeared in his viewfinder). The index here (a material entity motivating abductive inferences) is the painting on the wall done by an unknown Timorese artist. The prior index is the photograph of Che taken by Korda. While the prototype is Che Guevara, the virtual prototype is (for the Timorese artist) is Xanana Gusmao. This Timorese artist is inspired by the Korda image: it acts on him/her and makes him/her its recipient. At the same time, the public and possibly those censoring institutions of the establishment are also recipients that may either be incited to violence if they understand the artifice at play, or simply allow the mural to pass. Those who understand the process of "masking as survival under colonization" (Sandoval, 2000, p. 84) and the place of the "trickster who practices subjectivity as masquerade..."(Sandoval 2000, p. 62) are those who have developed skills of semiotics as resistance and a consciousness that can identify oppositional expressions of resistance.

There is a constant oscillation between the material and virtual of the image. This shimmering is especially salient when the intent is one of imputed similarity signalled through the use of artifice to create a parallelism that can be recognized by those interested in the subversive restructuring of knowledge and who hold an elective affinity with the oppressed. 


\section{REFERENCES}

Allingham, P. (2008). Urban Space, Representation, and Artifice. Knowledge Technology Policy, 21,163-174.

Anonymous. (1999). A Heroic Image: The Korda Photograph. University of North Carolina: School of Information and Library Science. Retrieved from: http:// ils.unc.edu/ michm/Che/korda.html.

Associated Press. (2006). "Che" Guevara's iconic image endures. The Washington Post: Associated Press, Saturday September 23.

Bal, M. (1998). Seeing Signs: The Use of Semiotics for the Understanding of Visual Art. In: M.Cheetham, M. A. H., and Moxey, K. (ed.) The Objects of Art History: Historical Objects in Contemporary Perspective.

Bal, M. (2003). Visual essentialism and the object of visual culture. Journal of Visual Culture, 2, 5-32.

Bal, M. \& Bryson, N. (1991). Semiotics and art history. Arts Bulletin, LXXIII, 174-208.

Barthes, R. (1973). Mythologies, Frogmore, St Albans, Herts: Paladin.

Barthes, R. (1977). Image, music, text, London: Fontana.

Barthes, R. (1981). Camera Lucida: reflections on photography, New York, Hill and Wang.

Barthes, R. (1988). The semiotic challenge, New York: Hill and Wang.

Baudrillard, J. (1992). "Strike of Events"” L'illusion de la fin: ou La greve des evenements [Online]. Paris. Retrieved from: www.uta.edu/english/apt/collab/texts/ strike.html.

Bryson, M. B. A. N. (1991). Semiotics and art history. Arts Bulletin, 73, 174-208.

Chandler, D. (2002). Semiotics: the basics, London: New York, Routledge.

Culler, J. (1974). Introduction. Course in General Linguistics. New York Philosophical Library.

Danesi, M. (1991). Teaching semiotics: The Textbook issue. The Semiotic Review of Books, 2, 6-7.

Danesi, M. \& Perron, P. (1999). Analyzing cultures: an introduction and handbook, Bloomington, Indiana University Press.

Derrida, J. (1976). Of grammatology, Baltimore, Johns Hopkins University Press.

Derrida, J. (1978). Structure, sign and play. In: (Trans.) Writing and Difference. London \& New York: Routledge.

Derrida, J. 1987. The truth in painting. Chicago, University of Chicago Press.

Eco, U. (1976). Peirce's Notion of Interpretant. MLN, 91, 1457-1472.

Eco, U. (1984). Semiotics and the philosophy of language, Bloomington, Indiana University Press.

Florensky, P. (1996). Iconostasis, Crestwood NY, St Vladimir's seminary press. 
Foucault, M. (1983). This is Not a Pipe, Berkeley, University of California Press.

Futoransky, L. (1999). "Xanana Gusmao, el Che de la jungla” in Letralia: Tierra de Letras. No. 84 (December, 20). Retrieved from: http://www.letralia.com/84/ar01-084.htm.

Gasché, R. (1986). The Tain of the Mirror: Derrida and the philosophy of reflection. Boston: Harvard University Press.

Gel, A. (1998). Art and agency: an anthropological theory. Oxford: Clarendon Press.

Greimas, A. J. (1987). The Interaction of Semiotic Constraints. In: P.J. Perron and Frank.

Guevara, E. 2002. Obra completa del Che, Buenos Aires: Andromeda.

Guevara, E. 2003. El diario de Che en Bolivia, La Habana: Editora Politica.

Guevara, E. \& Casaus, V. 2004. Self-portrait: Che Guevara, Melbourne, AU, New York, Havana, CU: Ocean Press: Centro de Estudios Che Guevara.

Hopkins, G. M. (1985). On the Origin of Beauty: A Platonic Dialogue (1865). In: (1953), W. H. G. (ed.) Abridged version in Poems and Prose of Gerard Manley Hopkins. New York: Penguin Classics.

Jakobson, R. (1976). A few remarks on structuralism. $M L N$, 91, 1534-1539.

Jay, M. (2002). Cultural relativism and the visual turn. Journal of Visual Culture, 1, 267-278.

Krauss, R. (1999). Reinventing the medium. Critical Inquiry, 25, 289-305.

Levinas, E. (1987). Reality and its shadow. In: Lingis, A. (ed.) Collected Philosophical Papers. The Hague: Martinus Nijhoff Publishing.

McCarthy, T. (2000). The Cult of Gusmao. TIME Magazine U.S. Online. (Monday March 20).

Retrieved from: http://www.time.com/time/magazine/article/0,9171,996371,00.html

McCormick, G. H. (1997). Che Guevara: The legacy of a revolutionary man. World Policy Journal. 1997/98, 63-79.

O'Toole, M. (1994). The language of displayed art, Rutherford: Fairleigh Dickinson University Press.

Parmentier, R. (1985). Semiotic Mediation: Sociocultural and Psychological Perspectives. Eds.

Elizabeth Mertz and Richard J. Parmentier. Orlando, FL: Academic Press.

Peirce, C. S. (1985). Logic as Semiotic: The Theory of Signs In: INNIS, R. E. (ed.) Semiotics: An anthology. Bloomington: Indiana University Press.

Petrilli, S. \& Ponzio, A. (2005). Semiotics unbounded: interpretive routes through the open network of signs, Toronto; Buffalo: University of Toronto Press.

Portis-Winner, I. (1999). The dynamics of semiotics of culture: its pertinence to anthropology. Sign Systems Studies, 27, 24-45.

Preziosi, D. (1992). The question of art history. Critical Inquiry, 18, 363-386.

Preziosi, D. (2003). Brain of the Earth's Body: Art, Museums, and the Phantasms of Modernity, 
Minneapolis \& London: University of Minnesota Press.

Price, M. (1994). The photograph. A strange confined place, Stanford: Stanford University Press.

Rancière, J. (1992). On the Shores of Politics, London, New York: Verso.

Rogers, B. (2002). Timor: A Nation Reborn by Bill Nicol. Asian Review of Books. Retrieved from: $\mathrm{http}: / /$ www.asianreviewofbooks.com/new/?revID=138

Saussure F. D. (2006). Writings in general linguistics, London; New York, Oxford University Press.

Sheilds, R. (2003). The Virtual. London and New York NY: Routledge.

Sheilds, R. (2005). The virtuality of urban culture: Blanks, dark moments and blind fields. Soziale Welt 16: Die Wirklichkeit der Städte Badenbaden, Ger.: Nomos Verlagsgesselschaft.

Sidnell, M. J. (2008). Semiotic Arts of Theatre. Semiotica, 168, 11-43.

Simmons, G. (2009). "East Timor - I was there before it became big" Travel Blog. Retrieved from: http://www.travelblog.org/Asia/East-Timor/Dili/blog-374557.html

Skagestad, P. (1998). "Peirce, Virtuality, and Semiotic" in Proceedings from The Twentieth World Congress of Philosophy, 10-15 August 1998 Boston, Massachusetts U.S.A.

Sonesson, G. (2003). An essay concerning images. From rhetoric to semiotics by way of ecological physics. Retrieved October 10, 2006, from

http://www.arthist.lu.se/kultsem/pdf/Groupe_My_review.pdf

\footnotetext{
${ }^{\mathrm{i}}$ Having said this, the domain of contemporary semiotics has developed so vastly even since the modern moments with Saussure and Peirce that taking up the conversation any further back becomes unwieldy unless there is a specific purpose. Yet, I cannot resist mentioning the intriguing medieval proposal put forth by the French theologian Peter Abelard (1079-c. 1142) who suggested that, "the 'truth' that a sign purportedly captured existed in a particular object as an observable property of the object itself, and outside it as an ideal concept within the mind. The 'truth' of the matter, therefore, was somewhere in between" (Danesi \& Perron, 1999 p. 43). Almost one thousand years ago, Abelard had grasped and expressed the complexity of perception in a way that did not create a dualism like the materialist or idealist poles seem to do, and that gestured toward a third position anticipating later developments of the Saussurean and Peircian models.
}

ii The term semiotic black market expresses the essence of artifice, and was coined by conceptual artist Vik Muniz: "I grew up in Brazil in the seventies, under a climate of political repression during military regime. You're forced to live in a sort of a semiotic black market, where you can never say what you really mean and everything that you hear is not what really is." - Vik Muniz

http://www.ted.com/talks/vik_muniz_makes_art_with_wire_sugar.html

iii Etymologically, artifice has three different routes/roots, one is as the Greek techné, (TEKHNE) who was the goddess or the spirit (daimona) of art, technical skill and craft. Another derives from the word for artifice, stratagem, or plan: metis (may'-tis). Odysseus (or "Ulysses") is associated with metis in the Homeric Epics as polymetis, or "man of many wiles" and the famous strategem (metis) of the Trojan horse. Finally, there is the Latin root, artificium "making by art, craft," from artifex (gen. artificis) "craftsman, artist," from ars "art" (see art (n.)) + facere "do" (see factitious): meaning "device, trick" (the usual modern sense). Other definitions include: artifice, to name or make by art: An ingenious expedient, a man \{oe\}uvre, stratagem, device, contrivance: human skill as opposed to what is natural. 
${ }^{\text {iv }}$ By structure of the sensible, Rancière is making a Platonic link to the later dialogues particularly the Timaeus.

${ }^{v}$ Hopkins: “... perhaps we shall be right to say all artifice, reduces itself to the principle of parallelism. Now the force of this recurrence is to beget a recurrence or parallelism answering to it in the words or thought and, speaking roughly and rather for the tendency than the invariable result, the more marked parallelism in structure whether of elaboration or of emphasis begets more marked parallelism in the words and sense. (81-2) To the marked or abrupt kind of parallelism belong metaphor, simile, parable, and so on, where the effect is sought in likeness of things, and antithesis, contrast, and so on, where it is sought in unlikeness (41)

85- relevance and importance of ambiguity- intrinsic

87- "In referential language the connection between signans and signatum is overwhelmingly based on their codified contiguity, which is often confusingly labeled 'arbitrariness of the verbal sign.'146 "Of the three different sorts of Parallels' viewed by Lowth, 'every one hath its peculiar character and proper effect' (xxvii). Synonymous lines 'correspond one to another by expressing the same sense in different, but equivalent terms; when a Proposition is delivered, and it is immediately repeated, in the whole or in part, the expression being varied, but the sense entirely, or nearly the same' (xi).

Two antithetic lines 'correspond with one another by an Opposition sometimes in expressions, sometimes in sense only. Accordingly the degrees of Antithesis are various; from an exact contraposition ... down to a general disparity, with something of a contrariety, in the two propositions' (xix).

... congruences, which he calls 'Synthetic or Constructive' and 'where the Parallelism consists only in the similar form of Construction." The verses are bound by a mere "correspondence between different propositions, in respect of the shape and turn of the ... and of the constructive parts" (xxi) Sound symbolism is an undeniably objective relation founded on phenomenal connection between different sensory modes, in particular between the visual and the auditory experience.

89- " Charles Sanders Peirce: "This clothing never can be completely stripped off; it is only changed for something more diaphanous"

110-"In manipulating these two kinds of connection (similarity and contiguity) ...an individual exhibits his personal style, his verbal predilections and preferences. Parallelism is "- a correspondence" -impressive range of possible configurations.

${ }^{\text {vi }}$ In 1902, Charles S. Peirce defined virtual as: 'A virtual $\mathrm{X}$ (where $\mathrm{X}$ is a common noun) is something, not an X, which has the deficiency (virtus) of an X.' (see also Edmund Burke's doctrine of virtual representation, which is not representation but is supposedly as good as.)

${ }^{\text {vii }}$ For Rob Shields, there are some core assumptions he builds on: first, the virtual "is neither absence nor an unrepresentable excess or lack" (20); second, reality is not a monolithic thing it needs to be treated as "more fine-grained concepts" (20) so that the real can be seen as multiple and more than simply the tangible "allowing us to being to conceptualize processes such as becoming in terms of emergence and dialogism (cf. Bakhtin, 1981 in Shields, 21); and third we are already accustomed to "day-to-day manipulation of virtual and actual objects" (Shields, 20) so that we can see ourselves as literate in terms of understanding the virtual though we may not have come to an explicit structuring of those knowledges.

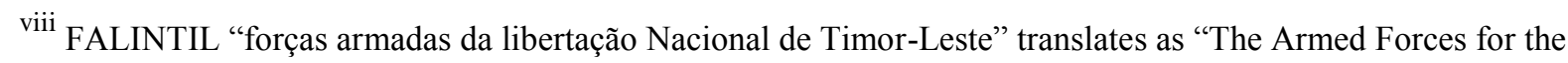
National Liberation of East Timor" originally began as the military wing of the leftist political party FRETILIN. 